\title{
Designing a Research Infrastructure with Impact in Mind
}

\author{
Silvia Vignetti
}

\section{Contents}

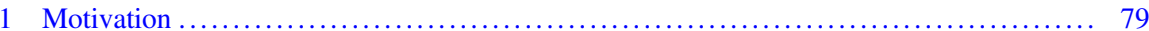

2 An Increasing Demand of Socio-Economic Impact Assessment .................... 79

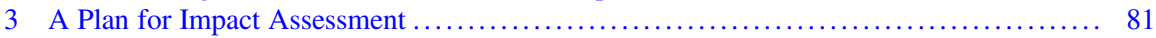

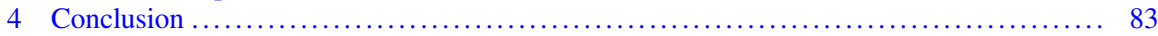

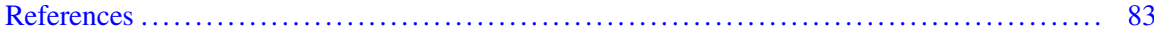

\section{Motivation}

Assessing the socio-economic impact of a Research Infrastructure (RI) requires an evaluation framework and a data collection plan that should be put in place as early as possible. This essay maintains the idea that if data collection for impact assessment is not episodic, motivated by external requests from stakeholders and funding agencies, but rather becomes a routine activity, it could maximize its potential to inform the RIs management and serve the strategic planning function of the infrastructure.

\section{An Increasing Demand of Socio-Economic Impact Assessment}

There is an increasing demand of demonstrating the expected socio-economic impacts triggered by research infrastructures already during the preparatory phase. Traditionally, the case for funding a new or upgraded RI has been usually advocated by scientific collaborations often supported by peer reviews exercise on the basis of a

\footnotetext{
S. Vignetti $(\bowtie)$

Development \& Evaluation Studies, Centre for Industrial Studies, Milan, Italy

e-mail: vignetti@csilmilano.com 
scientific case [1]. More recently, ex-ante impact assessment is becoming a routine analysis complementing the scientific and business cases accompanying the request for public funding (see for example the ESFRI Roadmap Guide 2021 and the Proposal Submission Questionnaire) [2, 3].

The fact that RIs can demonstrate their contribution to socio-economic development beyond the primary objective of excellent science is becoming crucial in the increasing international competition of hosting countries [4, 5]. The importance of promoting science facilities as a hub of knowledge and innovation within a wider ecosystem with a relevant territorial dimension is fully embraced by the EU Cohesion Policy. Investments funded by the European Structural and Investment funds for RIs should be planned however in the context of wider national or regional innovation strategies (according to the smart specialisation approach).

Against this background, evidence from a recent survey collecting almost 200 questionnaires from RI managers in the context of the Ri-Paths project, ${ }^{1}$ indicates that $40 \%$ of respondents have some experience with socio-economic impact assessment [6]. However, only half of them carry out impact assessment on a regular basis, while the remaining ones only episodically and upon request. The main motivation is the need to comply with formal procedures for funding applications. Internal initiatives include mostly the need for strategic evaluation and reporting rather than ensuring public accountability. In addition, in the majority of cases, the socio-economic impact assessment has been carried out internally with own resources and only in few cases externally contracted to professional experts.

More widespread is the practice of performance monitoring as a routine reporting tool to funding agencies for accountability purposes. When looking at existing practices for data collection and monitoring based on respondents' experience, the survey found that $41 \%$ collect data for management and compliance purposes based on a list of key performance indicators (KPIs), while only 9\% collect impact indicators for the purpose of impact assessment exercises.

Impact assessment is linked but not identical to monitoring: performance monitoring is rather a continuous process generating data to track the progress of an action while impact assessment is a structured process that takes place at a given point in time allowing to assess the implications (past, future or both), of proposed actions. Monitoring indicators can be useful input to impact assessment exercises but shall not be confused with impact indicators.

Many RI managers reported that a systematic procedure to ensure efficient data collection and monitoring is not done in the majority of cases and among the main barriers to perform such activities there is the lack of internal resources and expertise. As a matter of fact, especially for large and multi-purpose facilities, there is the need for deep understanding and collaboration of different managers in the same RI to engage in a systematic data collection activity.

${ }^{1}$ https://ri-paths.eu 


\section{A Plan for Impact Assessment}

Setting up a plan for impact assessment means deciding the roles (who does what), the timing (when: ex-ante, in itinere, ex-post, routinely every a number of years, etc.), the types of impact that are assessed (one or a sub-set in particular, all of them), which methods and techniques are used (with the related data collection methods and tools) and what is the expected use of the results in terms of feedback on strategy and management.

Currently there is no unique methodological framework for socio-economic assessment of RI but a variety of methods are used depending on the scope of the analysis, the type of impacts and the target users. Methods range from macroeconomic modelling to cost-benefit analysis to more qualitative narratives and case studies [7].

Despite different methodological approaches there is some consensus about the main impact areas (see [8-12]):

- Scientific impact

- Education impact

- Technological spillover and innovation

- Cultural and outreach

- Science as a public good

For each of these items a short list of common indicators and tools for data collection can be identified (see Table 1). The list can be adjusted and expanded/ restricted according to the specific need and remit of the assessment as well as the nature and type of activities of each RI.

As can be seen from the table below systematic tracking of scientific publications and citations, procurement contracts, patents and other innovation output, visitors and doctoral students, social media output and other dissemination products are the basis for a solid assessment and the condition for evaluability. In addition, regular surveys to former students, supplier companies and other users help to grasp useful insights on the way impacts materialise and how to maximise them. They require data collection strategies and evaluation plans. If a dedicated data collection plan is not in place, the ex-post reconstruction of past data can be challenging if not totally unfeasible. For example, getting in contact with students and researchers who spent time at a RI some years before might be impossible. Data protection issues are relevant in a number of cases, calling for a proper assessment and a rigorous management plan to ensure that there is no infringement to existing legislation.

For these reasons, setting up and implementing a plan for impact assessment from an early phase can make data collection more efficient and effective, despite some initial design costs. 
Table 1 Examples of common impact indicators and tools for data collection by main impact areas

\begin{tabular}{|c|c|c|}
\hline Impact area & Indicators & Tools for data collection \\
\hline $\begin{array}{l}\text { Scientific impact: The } \\
\text { value of knowledge } \\
\text { and its dissemination }\end{array}$ & $\begin{array}{l}\text { • N. of scientific publications } \\
\text { (in impacted/peer-reviewed } \\
\text { journals, periodicals, technical } \\
\text { reports, ..). } \\
\quad \text { - Of authors/scientists from the } \\
\text { RI or } \\
\quad \text { - Scientists using the RI } \\
\text { - N. of citations (track the wave of } \\
\text { knowledge dissemination) } \\
\text { - N. of attendees to conferences, } \\
\text { workshops, seminars } \\
\quad \text { - Origin and duration of stay } \\
\text { - Travel costs } \\
\text { - Time needed to produce/use sci- } \\
\text { entific outputs } \\
\text { - Yearly salary of scientists }\end{array}$ & $\begin{array}{l}\text { - Mandatory citation system } \\
\text { - Tracking system on existing } \\
\text { databases (web of science, } \\
\text { Scopus, PubMed, arXiv, INSPIR } \\
\text { E, etc..) based on word search }\end{array}$ \\
\hline $\begin{array}{l}\text { Scientific impact: Data } \\
\text { and ICT }\end{array}$ & $\begin{array}{l}\text { - N. of (FAIR) data content, open } \\
\text { source data/software } \\
\text { - N. of users/downloads } \\
\text { - Time spent in producing data or } \\
\text { ICT/time saved to reproduce or } \\
\text { process data } \\
\text { - Yearly salary of scientists }\end{array}$ & $\begin{array}{l}\text { - Mandatory citation system for } \\
\text { data and ICT tools } \\
\text { - Users surveys (users' communi- } \\
\text { ties) } \\
\text { - Tracking of downloads }\end{array}$ \\
\hline Education impact & $\begin{array}{l}\text { - N. of early career students/tech- } \\
\text { nical staff } \\
\text { - Origin and destination } \\
\text { - Skills acquired } \\
\text { - Short-term/long-term } \\
\text { - N. or attendees to trainings, } \\
\text { workshops, summer schools by } \\
\text { origin and duration of stay } \\
\text { - Travel costs } \\
\text { - Salary over a lifetime career } \\
\text { - Salary of a control group }\end{array}$ & $\begin{array}{l}\text { - Tracking system of students/ } \\
\text { alumni } \\
\text { - Systematic surveys to track } \\
\text { career paths and wage develop- } \\
\text { ment } \\
\text { - Systematic surveys to control } \\
\text { group (ethics and data protection } \\
\text { management) }\end{array}$ \\
\hline $\begin{array}{l}\text { Technological spill } \\
\text { over and innovation }\end{array}$ & $\begin{array}{l}\text { - N. of industrial suppliers } \\
\text { - Value of contract } \\
\text { - Year of contract } \\
\text { - Technological classification } \\
\text { of contract (high-medium-low) } \\
\text { - N. of industrial users or collabo- } \\
\text { rative projects with industry } \\
\text { - N. of spin-offs/start-ups } \\
\text { - Survival rate of spin-offs/start- } \\
\text { ups } \\
\text { - Incremental profit for new prod- } \\
\text { ucts/services/processes } \\
\text { - Patents } \\
\text { - Patents citations (backword and } \\
\text { foreword) }\end{array}$ & $\begin{array}{l}\text { - Systematic surveys to compa- } \\
\text { nies (with control groups) } \\
\text { - Systematic surveys to start-ups } \\
\text { and spin-offs } \\
\text { - Analysis of balance sheets } \\
\text { (e.g. Orbis database) } \\
\text { - Tracking of patents (e.g. } \\
\text { PATSTAT) }\end{array}$ \\
\hline
\end{tabular}


Table 1 (continued)

\begin{tabular}{|c|c|c|}
\hline Impact area & Indicators & Tools for data collection \\
\hline Cultural and outreach & $\begin{array}{l}\text { - N. of physical and virtual visitors } \\
\text { - N. of events, communication and } \\
\text { dissemination products and related } \\
\text { users } \\
\text { - Origin and duration of stay for } \\
\text { physical visitors } \\
\text { - Travel costs } \\
\text { - Time spent for virtual visits } \\
\text { (website/social media) }\end{array}$ & $\begin{array}{l}\text { - Tracking n. of visitors } \\
\text { - Survey to visitors } \\
\text { - Media tracking } \\
\text { - Web analytics }\end{array}$ \\
\hline $\begin{array}{l}\text { Science as a public } \\
\text { good }\end{array}$ & $\begin{array}{l}\text { - Contribution by member states } \\
\text { - Taxpayers by member states } \\
\text { - Willingness to pay for science }\end{array}$ & $\begin{array}{l}\text { - Surveys to citizens to assess } \\
\text { their willingness to pay }\end{array}$ \\
\hline
\end{tabular}

\section{Conclusion}

Socio-economic impact assessment of research infrastructure is a challenging and time-consuming activity. Yet, RI managers are increasingly faced by requests by funding agencies and policy makers to show the socio-economic impacts beyond the purely scientific one. For this reason, the collection of a well identified list of impact indicators shall be planned and implemented early in advance to avoid problems of unavailable or too expensive data to be produced on past actions. Including impact data collection within the routine activities for strategic management, not only will make the assessment exercise more efficient and effective, but would also increase its solidity and thus credibility as a strategic management tool.

\section{References}

1. Pancotti, C., Pellegrin, J. and Vignetti, S., 2014, "Appraisal of Research Infrastructures: Approaches, methods and practical implications", Department of Economics, Management and Quantitative Methods University of Milan Working Paper n. 2014-13.

2. ESFRI Roadmap Guide 2021, 2019.

3. ESFRI, Proposal Submission Questionnaire, 2018.

4. Macilwain, C., 2010. Science economics: what science is really worth. Nature 465, 682-684.

5. Scaringella, L., Chanaron, J., 2016. Grenoble-GIANT territorial innovation models: are investments in research infrastructures worthwhile? Technological Forecasting and Social Change, 112: $92-101$

6. Catalano, G., Vignetti, S., Ipolyi, I., DeYoung Becker, E. and Dostalova, Z., (2018). Survey of Research Infrastructures on impact assessment practices, RI-PATHS project, Brussels, https:// doi.org/10.5281/zenodo.3946309

7. Giffoni, F., Vignetti, S., 2019, Assessing the Socioeconomic Impact of Research Infrastructures: A Systematic Review of Existing Approaches and the Role of Cost-Benefit Analysis, L'industria, Fascicolo 1, gennaio-marzo. 
8. Giffoni, F., Schubert, T., Kroll, H., Zenker, A., Griniece, E., Gulyas, O., Angelis, J., Reid, A. and Vignetti, S., (2019), Literature review on socio-economic impact assessment of Research Infrastructures, RI-PATHS project, Brussels, https://doi.org/10.5281/zenodo.3946298

9. Florio, Massimo, Investing in Science. Social Cost-Benefit Analysis of Research Infrastructures, MIT Press, 2019

10. Martin, Ben R. 1996. "The use of multiple indicators in the assessment of basic research." Scientometrics, 36(3), 343-362.

11. Martin, Ben R., and Puay Tang. 2007. The Benefits from Publicly Funded Research. Science Policy Research Unit, University of Sussex, Brighton, UK.

12. Salter, A.J., Martin, B.R., 2001. The economic benefits of publicly funded basic research: a critical review. Res. Policy 30 (3), 509-532.

\section{Full Presentation}

https://indico.cern.ch/event/727555/contributions/3461268/attachments/1867486/3071404/FCC_ Week_DEF.pdf

Open Access This chapter is licensed under the terms of the Creative Commons Attribution 4.0 International License (http://creativecommons.org/licenses/by/4.0/), which permits use, sharing, adaptation, distribution and reproduction in any medium or format, as long as you give appropriate credit to the original author(s) and the source, provide a link to the Creative Commons licence and indicate if changes were made.

The images or other third party material in this chapter are included in the chapter's Creative Commons licence, unless indicated otherwise in a credit line to the material. If material is not included in the chapter's Creative Commons licence and your intended use is not permitted by statutory regulation or exceeds the permitted use, you will need to obtain permission directly from the copyright holder.

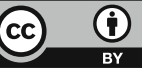

